\title{
Quality Improvement of Filter Product by Reducing Defect Printing Peel-off Area Seam (Case Study) in the Automotive Components Filter Industry
}

\author{
Sunadi $^{1}$, Martin Darmawan ${ }^{2}$,Else Paulina ${ }^{3}$ \& Sawarni Hasibuan ${ }^{4}$ \\ ${ }^{1-4}$ Master of Industrial Engineering Program, Mercu Buana University, Jakarta 11650, Indonesia
}

\begin{abstract}
The development of the automotive industry in the world continues to grow, including also the development of the automotive industry in Indonesia, along with the development of the business, supporting industries that supply components for parts used for automotive must prepare it, especially in terms of quality, quantity, and accuracy of delivery. There are still several automotive failures in terms of quality that have caused recall, it's as the reason why the research was conducted. Research carried out in one of the oil filter manufacturing industries where defect products namely peel off on the seaming area was reached $35.21 \%$ from the total amount of defects that occurred. The focus and purpose of the research are the effort to reduce printing defects. Several techniques are used in this research, such as work time measurement, line balancing approach, and some statistical tools for quality improvement, such as Pareto, fishbone diagrams, and why-why analysis. The result of the study was identified that the dominant cause of printing peel off on the seaming area was caused by the handling process on the packaging line when overlapping time. The handling process has been improved by reducing process handling with added transfer conveyors. The effectiveness of improvement has reported in March 2019 that the number of defect printing peels off the seaming area on oil filter products decreased by $46.74 \%$.
\end{abstract}

Key Words: Quality, Production Layout, Pareto, Fishbone Diagram, Why-Why Analysis.

\section{INTRODUCTION}

In an effort to maintain its existence and develop business amid increasingly fierce competition, every company must pay attention to the quality of the products it produces. As case study in automotive filter industry the research was conducted to see the improvement opportunities. Defect filter in this company was still found, as the fact in Figure 1.1.

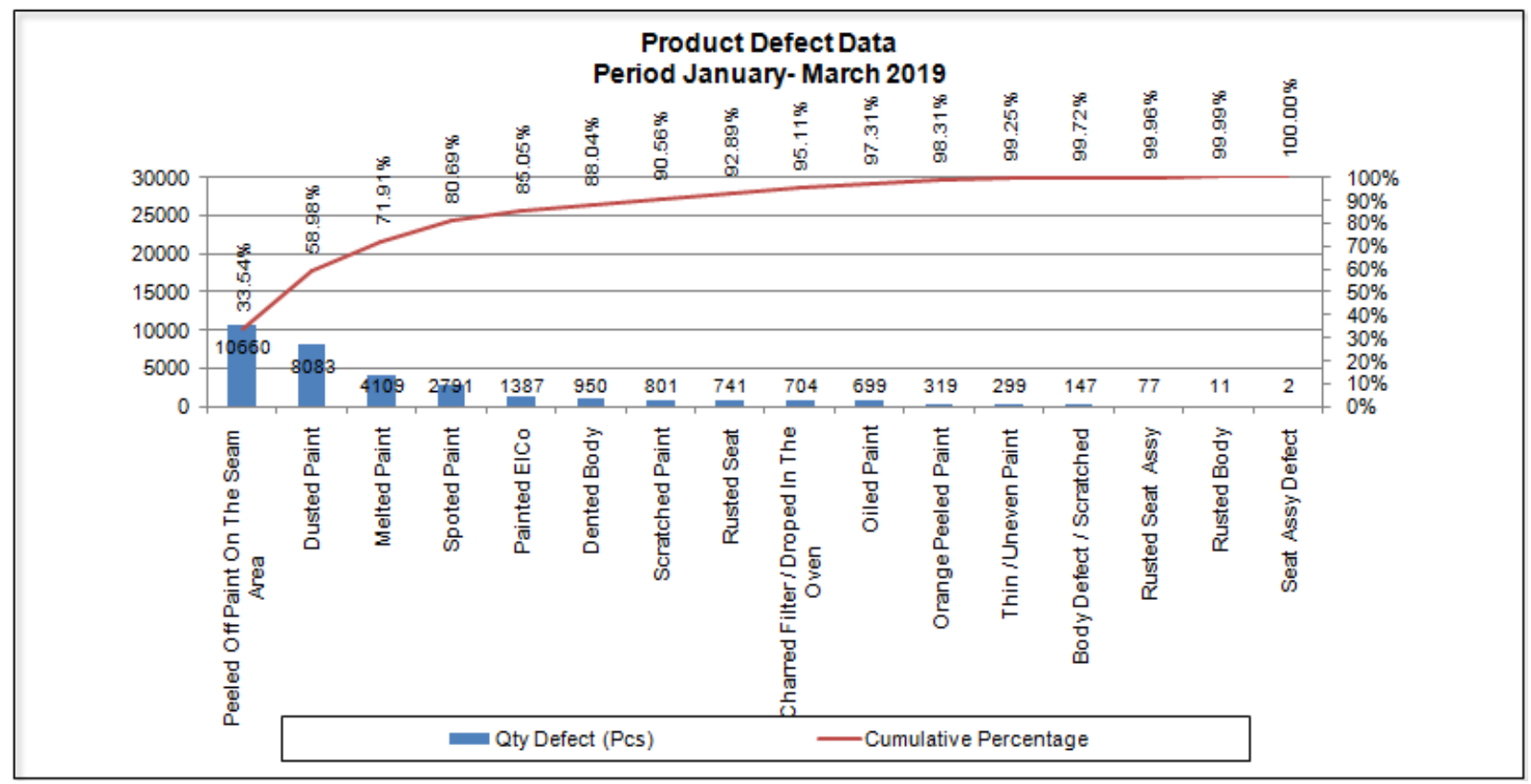

Figure 1.1: Defect Data for period January - February 2019

Based on Figure 1.1 above it can be seen that the defect mostly on the visual defects namely printing peel on the seaming area, it will become the focus of discussion in this study. The defect phenomenon happened due to any impact between one filter with 
other filters during a production process, which is printing peel off was caused by a collision. For making clear what happened with the filter defect, the printing peel defect is illustrated in Figure 1.2 below.

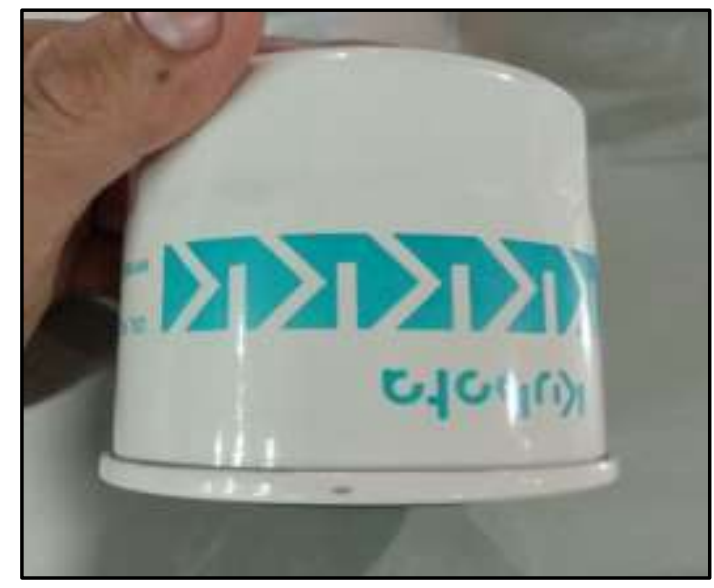

Figure 1.2: Printing Peel Off

The defect type as shown on Figure 1.2 above mostly happened on the filter type for NDL customer with the defect proportions as in Figure 1.3.

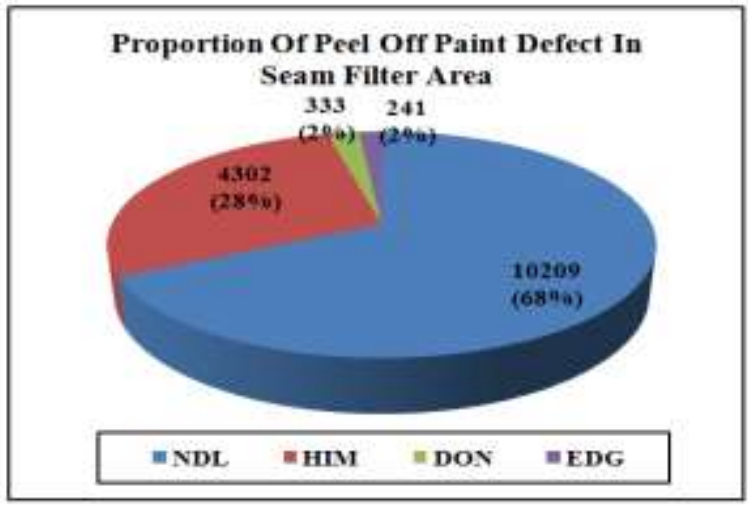

Figure 1.3: The defect proportion by customer.

As in Figure 1.3, The defect proportion of filter NDL has the biggest percentage, so the improvement was focused on it.

\section{LITERATURE REVIEW}

Quality is becoming important factor to retained the existing customers and also to build the customer in the future, the quality improvement is needed. There are many terminologies of quality improvement but there was no one of these can be covered whole recognition. Quality improvement is small thing done by all were involved on the company operation with resulted positive impact for the company [1]. Quality can be made by keeping good in production line balance [2]. Good layout or line balance will be contributed in reducing idle time in production [3]. To keep good quality, need to be well planned for production layout and need to be reviewed regularly [4]. Other opinion that not good in production layout planning will be created many losses [5]. Quality of product also can be created with good planning in material preparation [6]. Beside good planning in production layout and material preparation, quality also can be maintained by grouping material so it will avoid people wrong in material selection [7]. Quality must be kept well to retained loyal quality other ways will move to the competitor [8]. Important to keep the process stability and capability as continuous improvement in the production process [9]. The improvement tools need to be deployed in the company for making easier in trouble shooting practices to find out the correct root cause one of the many tool available is PDCA [10].

\section{METHODOLOGY RESEARCH}

The objective of research observed is to find out the root cause of the printing defect on seaming area case study on the filter manufacture. The type of research used in this study is descriptive of field findings during study. The study was conducted with the following steps: 
○ Collecting data

- Analyze data

- Determining the root cause

- Action for Improvement

- Conclusion and Recommendations.

Sequence detail for the methodology research as in Figure 3.1

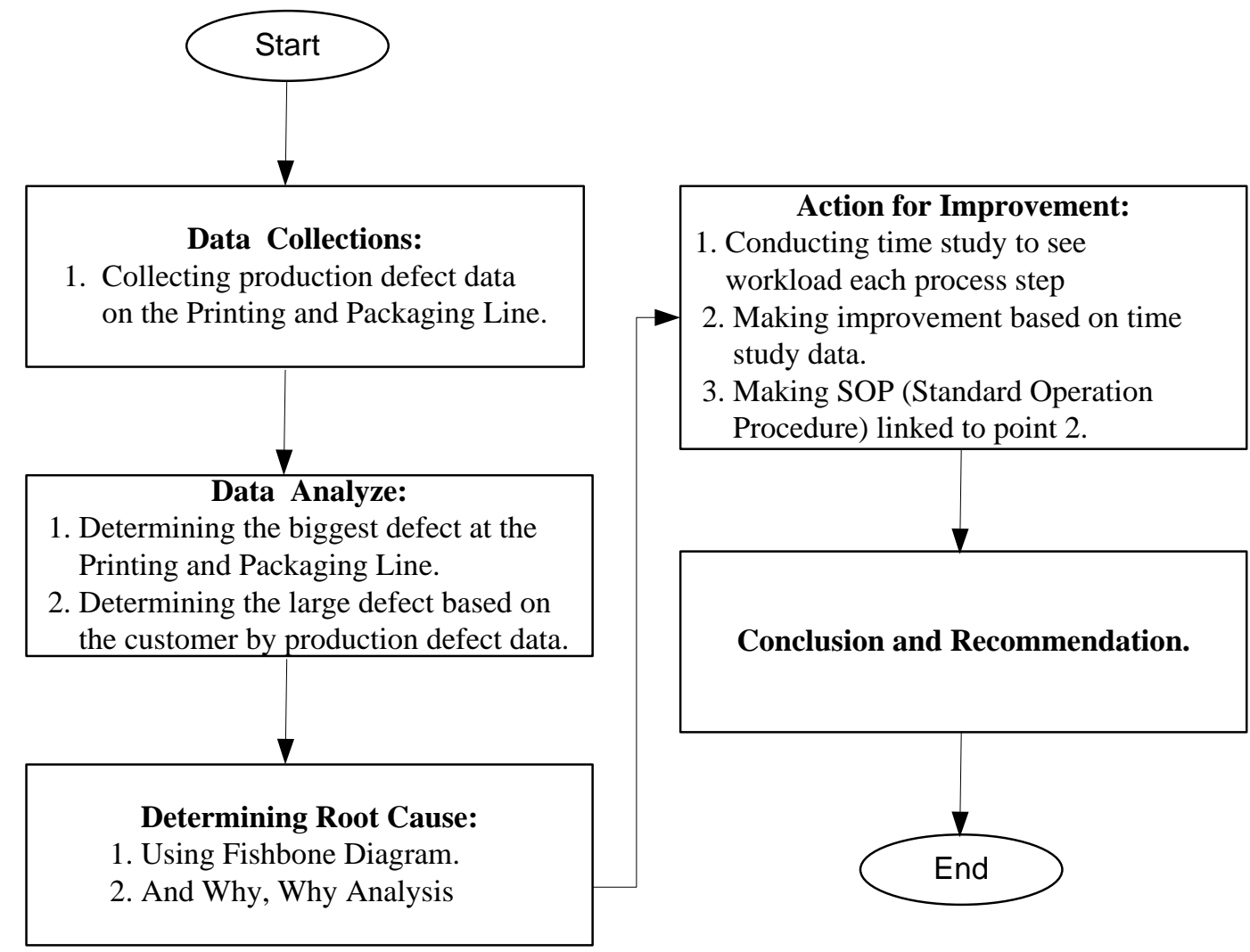

Figure 3.1: Flow of Research Methodology

\section{PRODUCTION FLOW PROCESS}

In conducting the production process, the layout applied namely a product layout, where the machines are made in sequence in the process of making one type of product. In this filter manufacture industry, the production lines are divided into several subproduction lines, each production line has a layout with a product layout form. The several production sub-lines are:

1. Paper pleating element production line,

2. Element assembly filter, Production line

3. Seaming filter production line,

4. Pretreatment filter production line,

5. Painting filter production line,

6. Packaging filter production line.

Because what will be discussed in this research is printing peel off defects, so the focus in this research is on the production subline after the painting filter production sub-line, which actually has a printing peel off defect in the seam area, that sub line namely the production subline filter packaging. And for the description of the production layout contained in the packaging filter sub-line in the automotive filter component company, it can be seen in the picture below. 


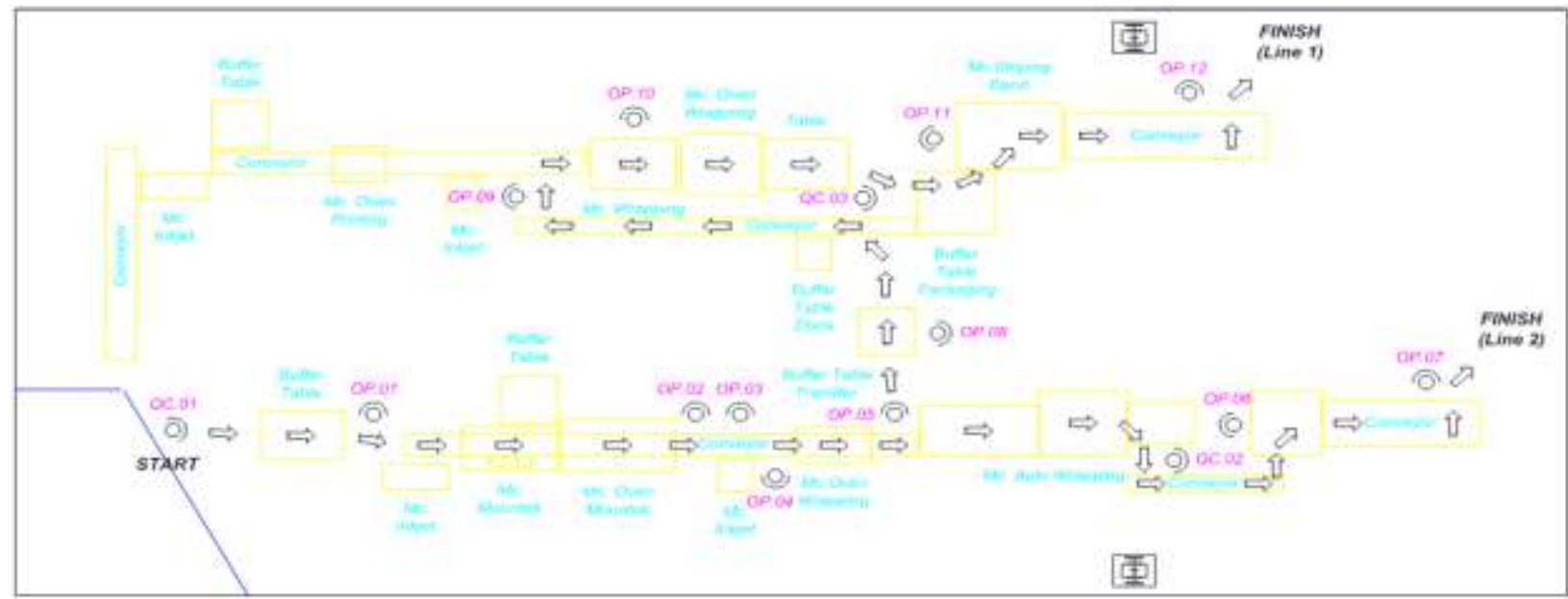

Figure 4.1: Production process flow in the packaging filter production line.

There are two production flow in the filter production process, namely filter packaging production lines 1 and line 2 . In the filter production process for NDL customers, there are obstacles namely during the wrapping process so that the process flow in the branch becomes 2 namely from the sub-line packaging production 1 is divided into packaging production sub-line 2 .

\section{ANALYSIS OF THE PROBLEM}

Based on the results of brainstorming between parts in the process of solving the problem of paint defects in the flaked seam filter area, then there are several potential sources of problems that occur. The description of the source of the problem can be seen in the following fishbone diagrams:

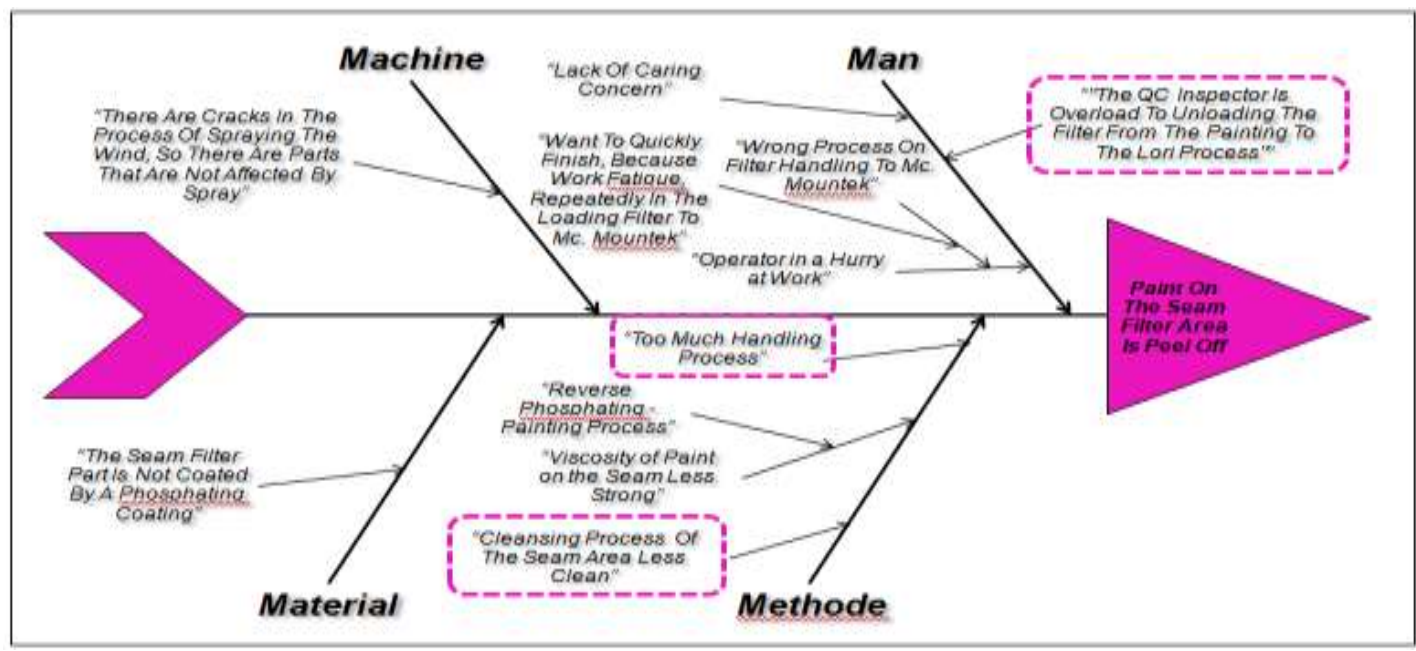

Figure 5.1: Fishbone diagrams for defect paint in the flaked seam filter area.

From the fishbone diagram it can also be seen the sources of the dominant causes that have been decided together. So the focus of repairs that will be done is to the sources of the dominant cause of the paint defect in the flaked seam filter area. After determining the sources of the dominant causes of the paint defect in the flaked seam filter area, then why-why analysis of the sources of the dominant cause of paint defect in the flaked seam filter area is then performed. As for why analyzes of these dominant factors are as follows: 


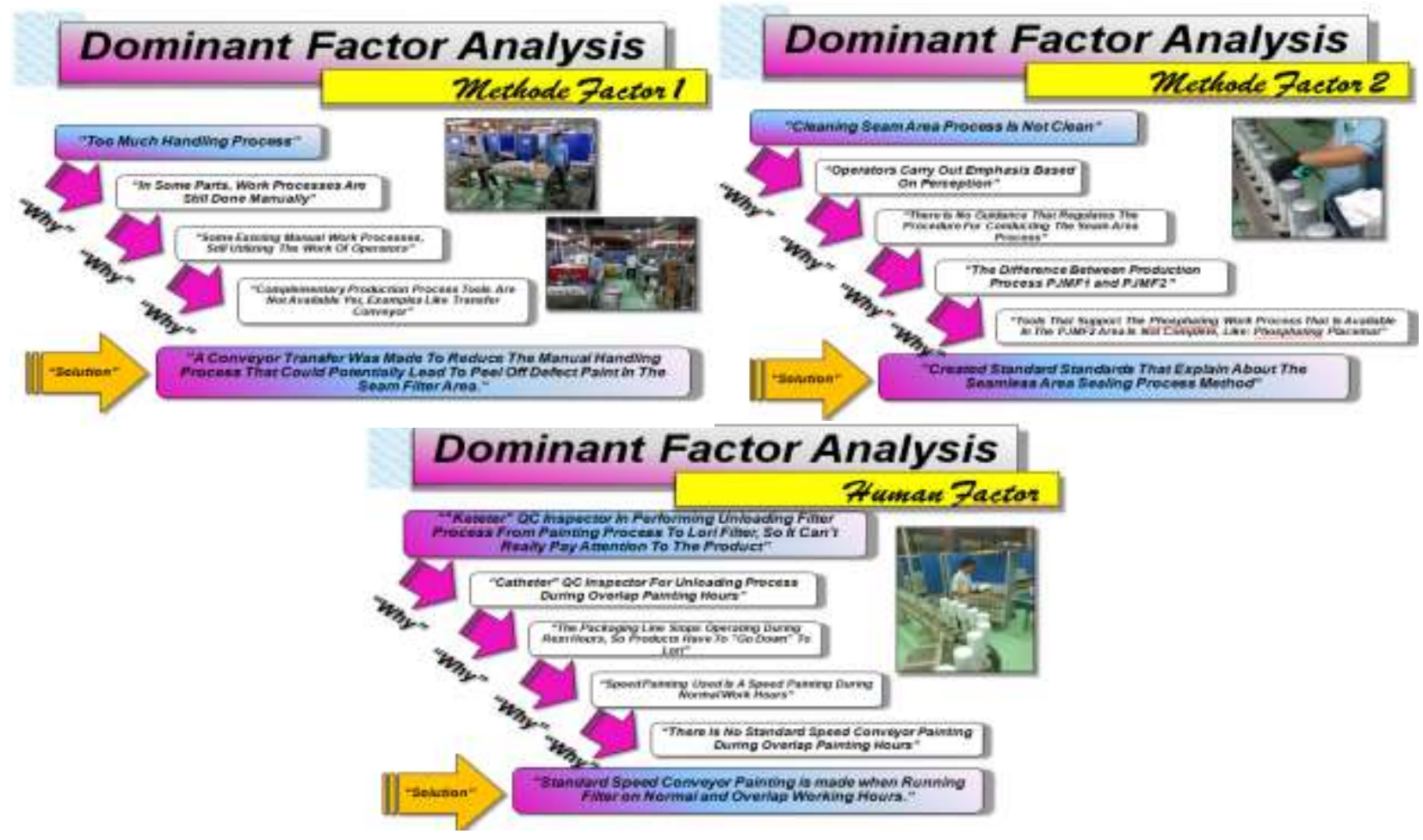

Figure 5.2: Why-why analysis for defect printing peel off area seaming.

\section{IMPROVEMENT}

Based on the 5 why-analyzes, the improvement steps for the printing defect are as follows:

\subsection{Improvement through reduction of excess handling process}

Reduction of excess handling process is done by replacing the excess handling process by using conveyor transfer. So that the potential for paint defects in the seam filter area is peeled off due to collisions caused by human factors can be reduced or even lost. The improvements that have been made are illustrated in the following figure:

\subsubsection{Condition before improvement}

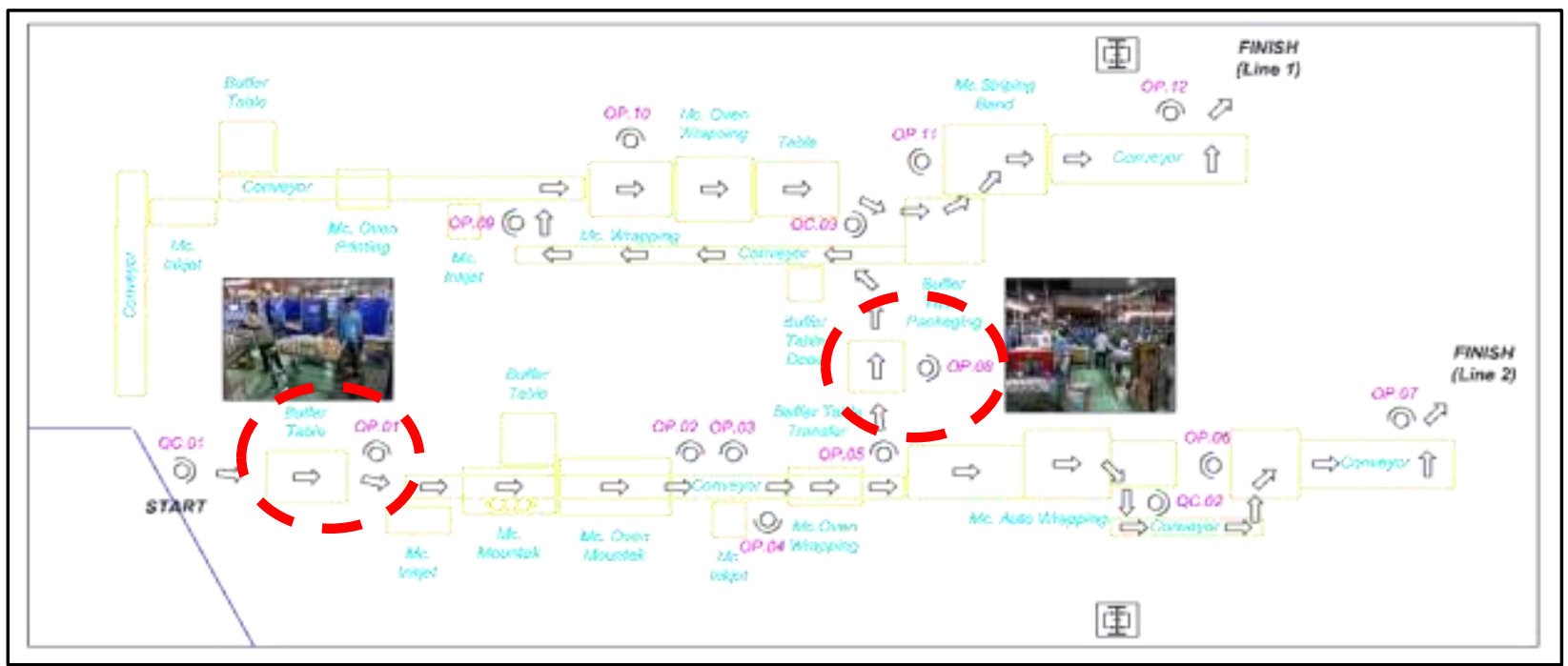

Figure 6.1: Layout and process flow in the actual packaging filter production line. 


\subsubsection{Conditions after Improvement}

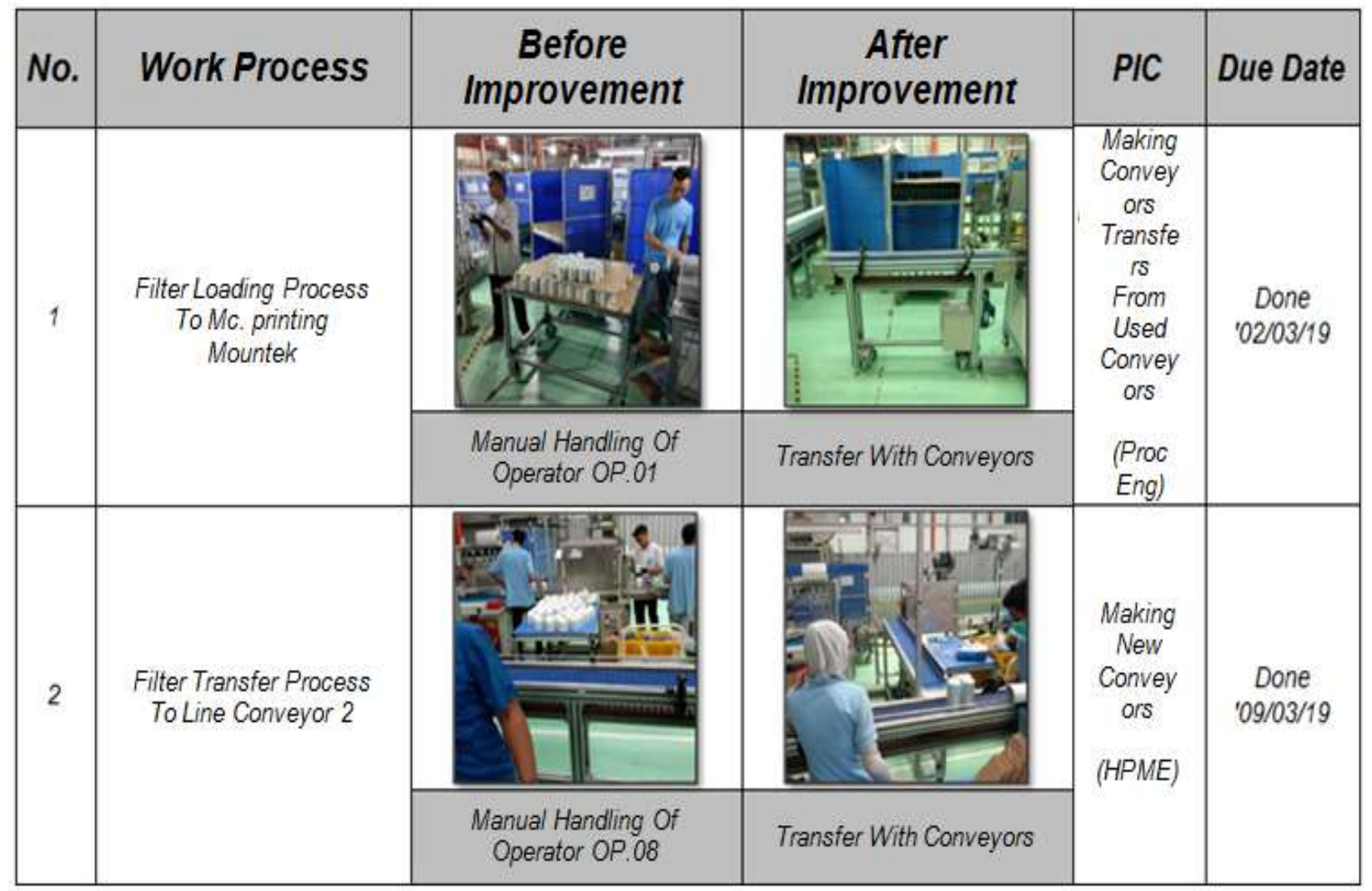

Figure 6.2: Improvement of the excess handling process.

After repairs, the layout will look like in Figure 6.3.

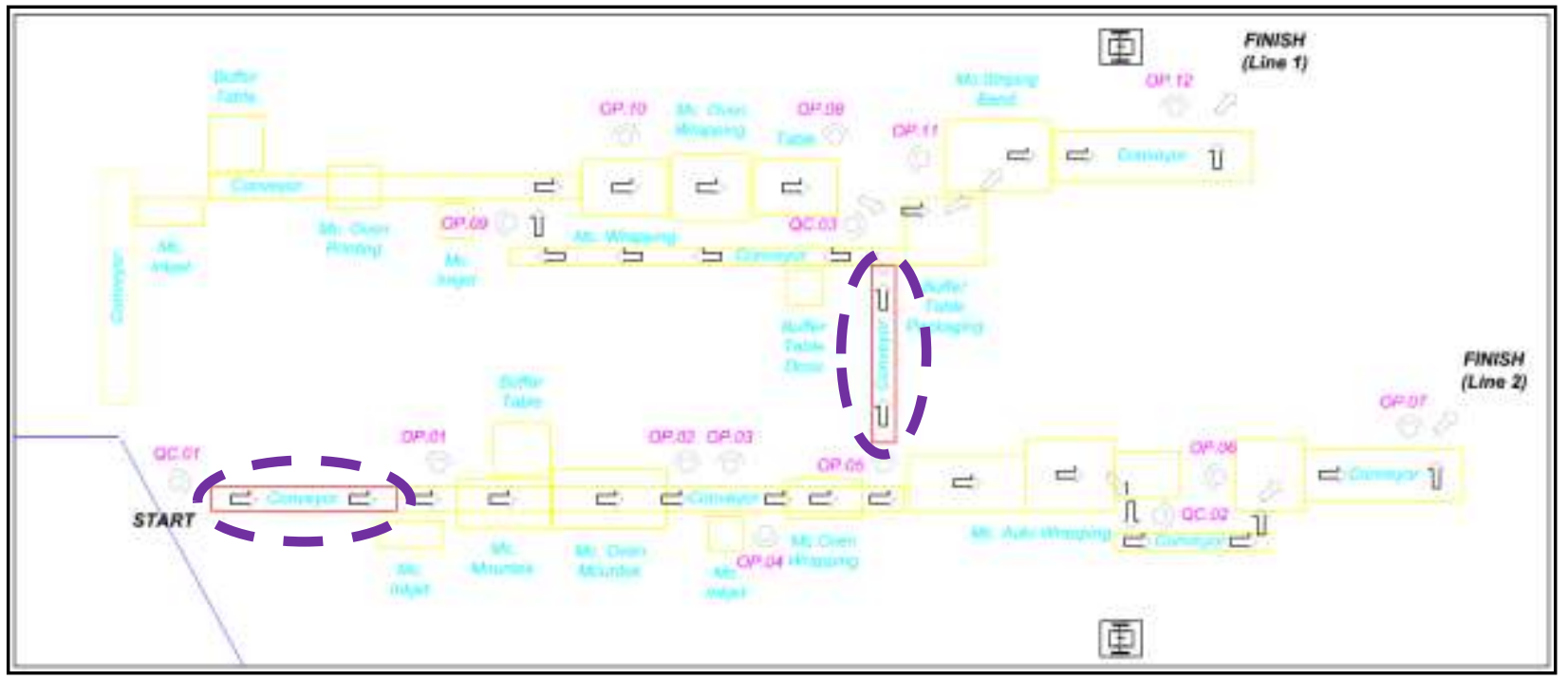

Figure 6.3: Layout and process flow in the packaging filter production line after repair.

After improving the data, it is known that there is a reduction in the handling process carried out by the production operator. This has implications for reducing the potential for paint defects in the seam filter area peeled off due to collisions caused by human factors. In addition to reducing the potential for defects, it turns out the transfer of the handling process carried out by the production operator into a conveyor transfer, also reduces the use of man power in the production process, thus providing more benefits than labor costs in the production line. 


\subsection{Improvement through standardization of the darkening process in the seam filter area}

Improvements to the darkening process of the seam filter area are carried out through the standardization process, by making a standard working procedure in the form of a Standard Operation Procedure (SOP) for the darkening process of the seam filter area. By making these written rules, it is expected to avoid errors caused by human factors, so as to reduce the variety of work done by the operator, both the stability of the workings of the operators, as well as differences in the workings between operators who work in the darkening of the seam filter area.

The description of the SOP process for sealing the area of the seam filter can be seen in the picture below:

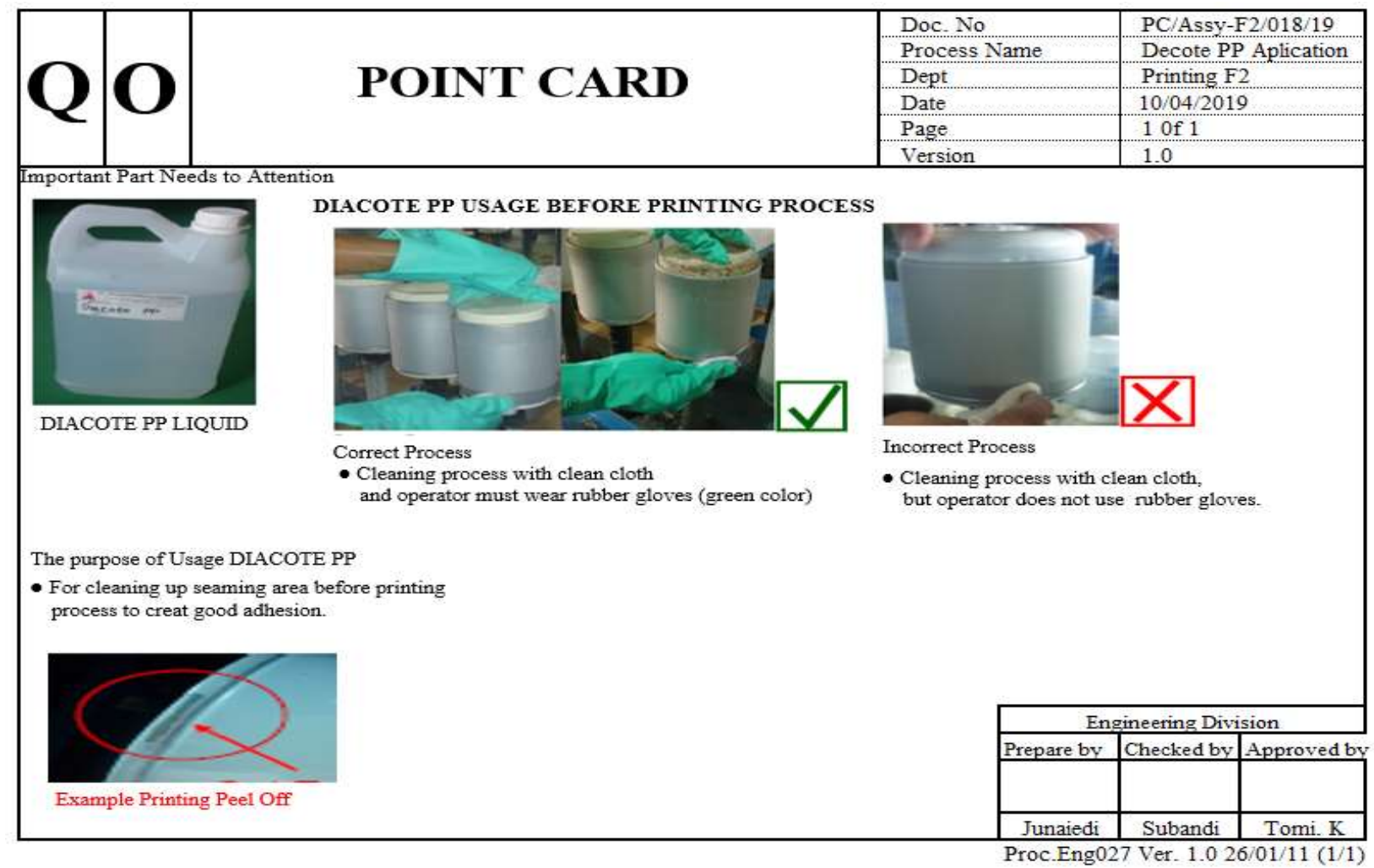

Figure 6.4: SOP for the area darkening process of the seam filter.

By doing the repair through the manufacture of SOP process of wiping area seam filter, the expected potential defect paint on the area of seam / body filter peeling caused due to irregularity of the workings of the process of wiping area seam filter can be reduced

\subsection{Improved standard process of painting the filter during working hours overlap}

process improvement painting filter when working hours overlap is done through changes in the standard speed of the painting process when working hours overlap the painting process. It is intended that the operator in charge of the unloading filter process from the painting process has a slightly more relaxed working time for placing the filter on the filter lorry, when the filter cannot directly enter the packaging process. The description of changes in the speed of the painting process during working hours overlap the painting process can take place can be seen in the picture below: 


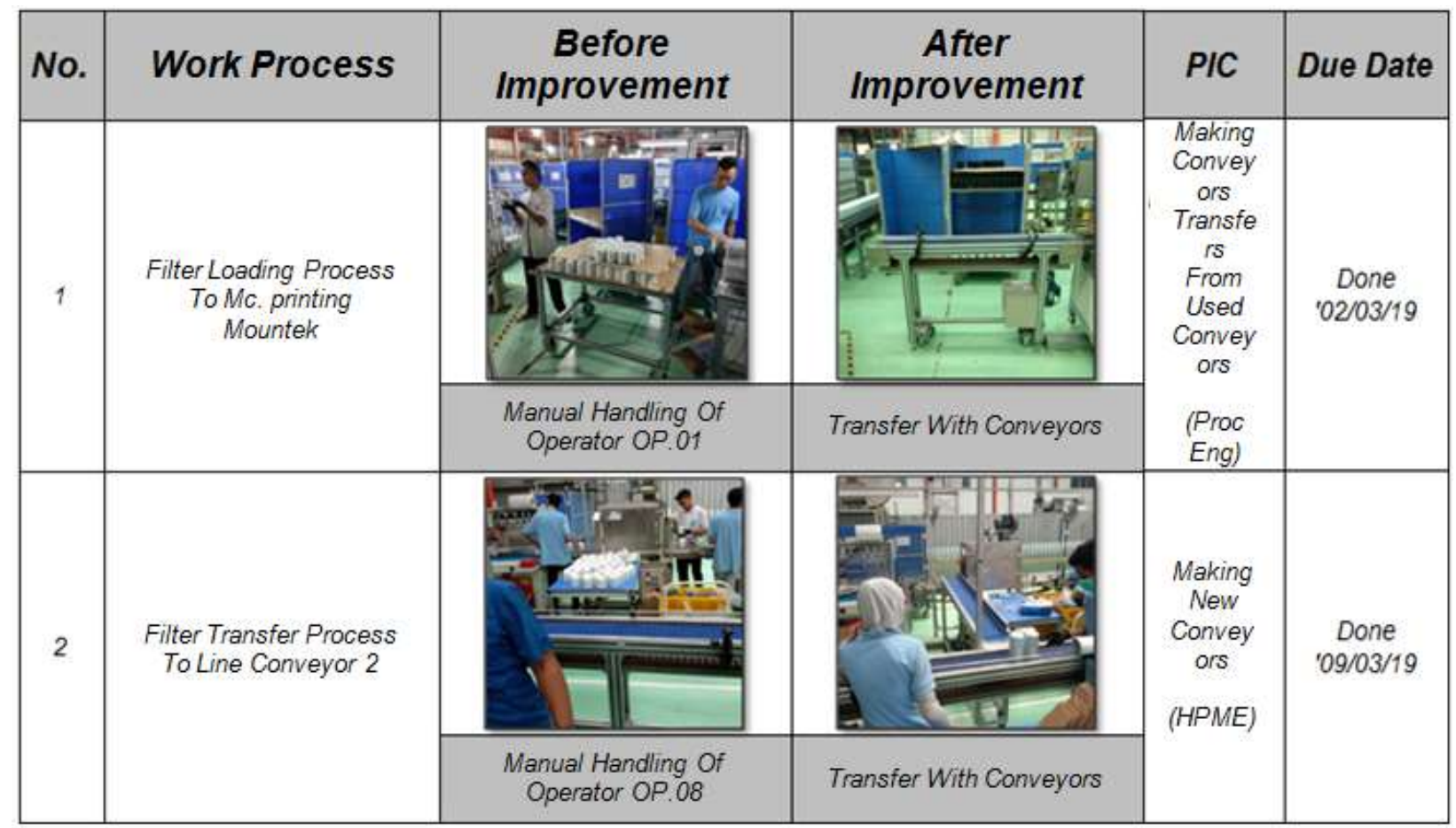

Figure 6.5: Improvements to the standard painting filter process when working hours overlap.

By making improvements to the speed of the painting process when overlapping takes place, it can reduce the potential for paint defects in the flaked seam filter area caused by factors of improper working methods, thereby reducing the human error factor caused by this.

\section{Effectiveness of Repair}

Based on the results of observations and data collection conducted on the effectiveness of the improvements that have been made in terms of reducing the amount of paint defects in the area of the flawed seam filter, through repairing the dominant factors causing the defect, it can be seen that the repair has been quite effective do. The description of the effectiveness of the improvements made to the dominant factors causing the paint defect in the flaky seam filter area can be seen in the figure below:

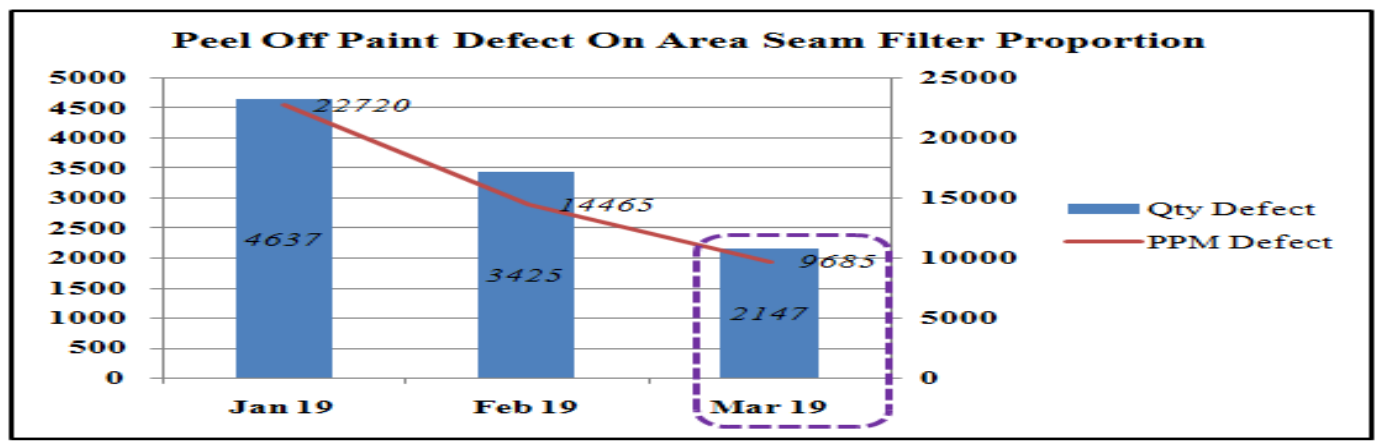

Figure 7.1: The effectiveness of repairing the paint defect in the flaked seam filter area.

From the results of observations and data collection it can be seen that there was a decrease in the amount of paint defects in the flaked seam filter area in the July 2019 period, where in that month period repairs were made. The decrease in the amount of paint defects in the flaked seam filter area that occurred in the July 2019 period reached $46.74 \%$ or in other words almost half of the average amount of paint defects in the flaked seam filter area that occurred in the previous month period. So that improvement can be said to have been effectively carried out.

\section{CONCLUSIONS AND RECOMMENDATIONS}

Based on the results and discussions, improvement that have been made is given a positive impact for company in reducing the number of defect printing peel off area seaming for product filter NDL type, the defect was decreased up $46.74 \%$ from the average of defected number in the first two months period of year 2019. Still has room to do an improvement on this filter industry, so for 
next researcher it is recommended to use the FMEA method to determining the root cause, because FMEA has RPN (Risk Priority Number) it will be more accurate in justification for the root cause, and for improvement sequence it can be used 5W1H method.

\section{REFERENCES}

[1]. Darmawan, H., Hasibuan, S., \& Purba, H. H. (2018). Application of Kaizen Concept with 8 Steps PDCA to Reduce in Line Defect at Pasting Process: A Case Study in Automotive Battery. International Journal of Advances in Scientific Research and Engineering, 4(8), 97-107.

[2]. Lam, NT, Toi, LM, \& Tuyen, VTT (2016). Lean line balancing for an electronics assembly line. Procedia CIRP, 40, 437-442

[3]. Dolgui, A., \& Gafarov, E. (2017). Some new ideas for assembly line balancing research. IFAC-PapersOnLine, 50(1), 22552259.

[4]. Hermawan, D. Increased Productivity of One Furnace Gas Stove through Improved Layout of Facilities at PT XYZ. Operations Excellence, 9(2), 152-163.

[5]. Rengganis, E. (2015). Comparison of Re-Layout Optimization for Production Facility Placement Using Craft to Minimize Material Handling Costs. Journal of Space, 7(1), 181-198.

[6]. Limbong, I., Tarore, H., Tjakra, J., \& Walangitan, D.R.O. (2013). Management of building material procurement using MRP (Material Requirement Planning) method Case Study: revitalization of BPS office building in North Sulawesi Province. Static Civil Journal, 1(6), 421-429.

[7]. Kashkoush, M., \& ElMaraghy, H. (2016). Product family formation by matching Bill-of-Materials trees. CIRP Journal of Manufacturing Science and Technology, 12, 1-13.

[8]. Nugroho, R.E., Marwanto, A., \& Hasibuan, S. (2017). Reduce product defect in stainless steel production using yield management method and PDCA. International Journal of New Technology and Research, 3(11), 39-46.

[9]. Schmidt, R.L. \& Pearson, L.N. (2019). Is your assay stable? Using process stability and capability to evaluate assay performance. Clinica Chimica Acta, 490, 28-33.

[10]. Riadi, S., Emerzet, S.E, \& Prasetyo, D. (2019). Reducing the number of reworks in the burritory process in line injection molding by the PDCA method. Operations Excellence, 11(2), 202-216. https://doi.org/10.22441/oe.v11.2.2019.030. 